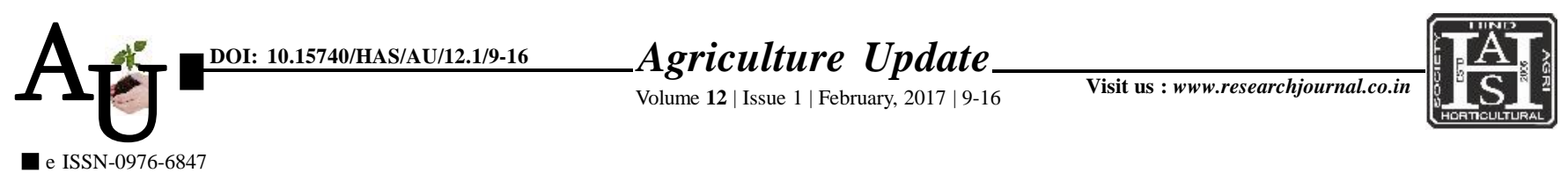

\title{
Research Article: Knowledge and adoption level of animal scientific practices by milk producers in Chhotaudaipur district of Gujarat
}

Article Chronicle:

Received :

15.11.2016;

Revised :

03.12.2016;

Accepted :

12.12.2016

KeY WoRDS :

Knowledge, Adoption, Milk producers, Animal scientific practices
SUMMARY : Livestock are an integral part of agriculture in India and are likely to be the instruments of future growth and development of the agricultural sector. They generate employment, provide draught power, manure and earn foreign exchange through exports. Additionally, livestock make substantial contributions to environmental conservation and provide domestic fuel to save on the use of petro-products. Although the per capita consumption of foods of animal origin is low in India, demand has been rising due to the growing human population, sustained growth in per capita incomes and increasing urbanization. Dairying is an integral part of the Indian economy providing subsistence to small and marginal farmers and landless laborers. Most of the rural farmers, who keep dairy animals, do not follow modern dairy management practices. This study was conducted on knowledge and adoption level of improved animal husbandry practices. Result revealed that majority of dairy farmers $(53.00 \%)$ had medium knowledge level, whereas 22.00 per cent and 25.00 per cent dairy farmers were having low and high knowledge level about improved animal husbandry practices, respectively. Majority of the members (51\%) were found to be medium adopters, while 27 per cent members were low adopters and 22 per cent of the members were high adopters.

How to cite this article : Dhayal, B.L. and Mehta, B.M. (2017). Knowledge and adoption level of animal scientific practices by milk producers in Chhotaudaipur district of Gujarat. Agric. Update, 12(1): 9-16; DOI : 10.15740/HAS/AU/12.1/9-16.
Author for correspondence :

\section{B.L. DHAYAL}

Krishi Vigyan Kendra, VADODARA (GUJARAT) INDIA

Email:dhayalextn@ yahoo.co.in

See end of the article for authors' affiliations 